Article

\title{
Endothelium-Independent Vasodilatory Effects of Isodillapiolglycol Isolated from Ostericum citriodorum
}

\author{
Tengshuo Luo ${ }^{1,+}{ }^{\text {, Zewei Chen }}{ }^{1, \dagger}{ }^{\text {, Fengyun Wang }}{ }^{2}$, Shanshan Yin ${ }^{3}$, Pan Liu ${ }^{3}$, Jun Zhang ${ }^{1, *}$ and \\ Zhonghua Yang ${ }^{4, *}$ \\ 1 School of Pharmaceutical Sciences, Guangzhou University of Chinese Medicine, Guangzhou 510006, China; \\ luots512@163.com (T.L.); czwbs007@163.com (Z.C.) \\ 2 Guangdong Pharmaceutical University, Guangzhou 510006, China; wfycn2000@163.com \\ 3 HEC Pharm R\&D Center, Dongguan 523871, China; shansy6@163.com (S.Y.); gzliupan@163.com (P.L.) \\ 4 Medical College of Acupuncture Moxibustion and Rehabilitation, Guangzhou University of Chinese \\ Medicine, Guangzhou 510006, China \\ * Correspondence: zhangjun@gzucm.edu.cn (J.Z.); yangzhonghua@gzucm.edu.cn (Z.Y.); \\ Tel.: +86-020-39356997 (J.Z.) \\ $\dagger$ These authors contributed equally to this work.
}

Received: 14 January 2020; Accepted: 14 February 2020; Published: 17 February 2020

check for updates

\begin{abstract}
Ostericum citriodorum is a plant with a native range in China used in herbal medicine for treating angina pectoris. In this study, we investigated the vasodilatory effects of isodillapiolglycol (IDG), which is one of the main ingredients isolated from O. citriodorum ethyl acetate extract, in Sprague-Dawley rat aortic rings, and measured intracellular $\mathrm{Ca}^{2+}\left(\left[\mathrm{Ca}^{2+}\right]_{\text {in }}\right)$ using a molecular fluo-3/AM probe. The results show that IDG dose-dependently relaxed endothelium-intact or -denuded aortic rings pre-contracted with noradrenaline (NE) or potassium chloride $(\mathrm{KCl})$, and inhibited $\mathrm{CaCl}_{2}$-induced contraction in high $\mathrm{K}^{+}$depolarized aortic rings. Tetraethyl ammonium chloride (a $\mathrm{Ca}^{2+}$-activated $\mathrm{K}^{+}$channel blocker) or verapamil (an L-type $\mathrm{Ca}^{2+}$ channel blocker) significantly reduced the relaxation of IDG in aortic rings pre-contracted with NE. In vascular smooth muscle cells, IDG inhibited the increase in $\left[\mathrm{Ca}^{2+}\right]_{\text {in }}$ stimulated by $\mathrm{KCl}$ in $\mathrm{Krebs}$ solution; likewise, IDG also attenuated the increase in $\left[\mathrm{Ca}^{2+}\right]_{\text {in }}$ induced by NE or subsequent supplementation of $\mathrm{CaCl}_{2}$. These findings demonstrate that IDG relaxes aortic rings in an endothelium-independent manner by reducing $\left[\mathrm{Ca}^{2+}\right]_{\text {in }}$, likely through inhibition of the receptor-gated $\mathrm{Ca}^{2+}$ channel and the voltage-dependent $\mathrm{Ca}^{2+}$ channel, and through opening of the $\mathrm{Ca}^{2+}$-activated $\mathrm{K}^{+}$channel.
\end{abstract}

Keywords: Ostericum citriodorum; isodillapiolglycol; vasodilation; endothelium-independent; $\mathrm{Ca}^{2+}$ channels

\section{Introduction}

Angina pectoris (AP) is defined as a clinical syndrome of temporary and rapid myocardial ischemia or anoxia caused by persistent coronary stenosis or spasm [1,2]. The mechanisms underlying AP might be multifactorial. NO released from vascular endothelial cells causes endothelium-dependent vasodilation, and significant endothelial damage might result in vasoconstriction and may induce AP $[3,4]$. Hypercontractility of vascular smooth muscle cells (VSMCs) has been shown to be strongly associated with $\mathrm{AP}$, and $\mathrm{Ca}^{2+}$ is the primary regulator of tension in VSMCs. There are two main types of channel in VSMCs: the receptor-operated $\mathrm{Ca}^{2+}$ channel (ROCC) and the voltage-dependent $\mathrm{Ca}^{2+}$ channel (VDCC). Activation of ROCC causes extracellular $\mathrm{Ca}^{2+}$ influx and intracellular $\mathrm{Ca}^{2+}$ $\left(\left[\mathrm{Ca}^{2+}\right]_{\text {in }}\right)$ release from the sarcoplasmic reticulum (SR), and activation of VDCC causes extracellular 
$\mathrm{Ca}^{2+}$ influx [5,6]. Until now, NO donor drugs (nitroglycerin) or $\mathrm{Ca}^{2+}$ channel antagonists (nifedipine) have mainly been used to treat AP in clinical practice [7,8]. Although efficient for treating AP symptoms to a certain extent, these agents do not provide relief in all patients with different conditions; therefore, a wider range of therapeutic agents is needed to treat AP than is currently available [9].

Ostericum citriodorum is a herbal medicine used to treat AP, coronary disease, and hypertension in China [10-12]. Its effect have been clearly recorded in China's Handbook of Common Chinese Herbal Medicine, National Compendium of Chinese Herbal Medicine, Cihai of Traditional Chinese Medicine, and Chinese Materia Medica dictionary. For example, the Huxin capsule, which is composed of $O$. citriodorum, has a good effect for treating AP in clinical practice [13].

In our previous study, we found that isoapiole, which was separated from the petroleum ether extract of O. citriodorum, relaxed the aortic rings in an endothelium-dependent manner [13]. A diversity of active ingredients and pathways are found in medicinal plants [14], and we further reported that the ethyl acetate extract of $O$. citriodorum exhibited an endothelium-independent vasodilatory effect $[15,16]$. In this research, we obtained isodillapiolglycol (IDG), one of the main ingredients from the O. citriodorum ethyl-acetate extract (OCE). On the basis of IDG possessing vasorelaxant activity, we investigated the mechanism of its vasodilatation by regulating $\left[\mathrm{Ca}^{2+}\right]_{\text {in }}$ in VSMCs.

\section{Results}

\subsection{Vasodilatory Effect of the Eight Major Fractions Obtained from O. Citriodorum Ethyl-Acetate Extract (OCE)}

In this primary experiment, we examined the vasodilatory effects of eight major fractions (Fr. A-H) obtained from OCE. The aorta rings were pre-contracted with noradrenaline (NE) $(3 \mu \mathrm{M})$, before adding Fr. A-H $(1000 \mu \mathrm{g} / \mathrm{mL})$. Among the eight fractions, Fr. F had the strongest vasodilatory effect (Figure 1).

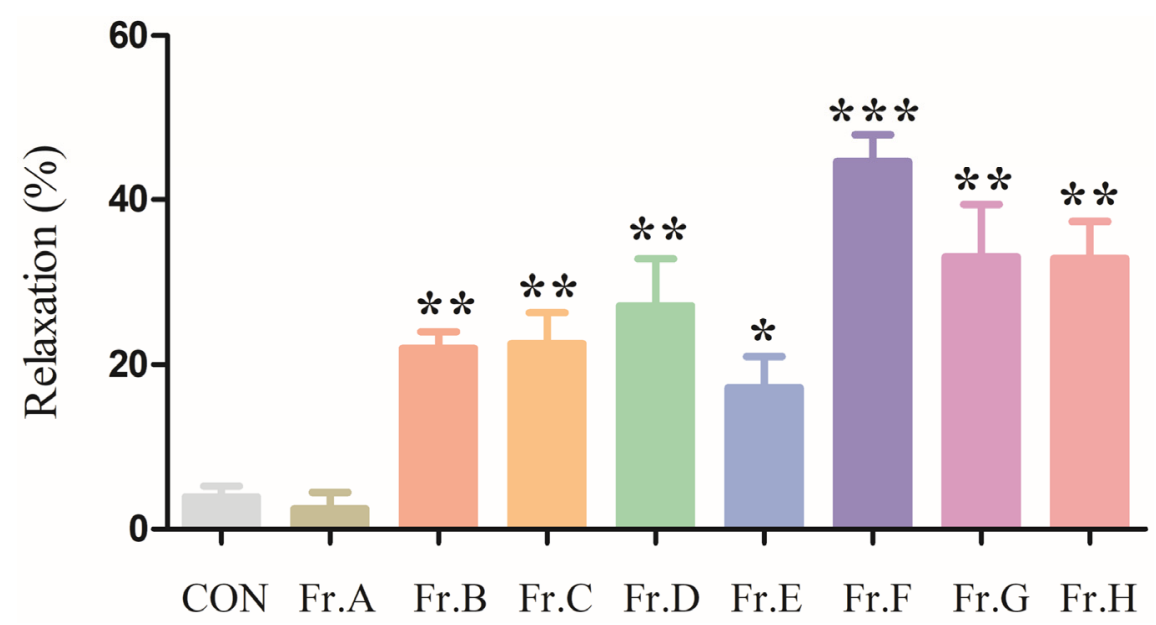

Figure 1. The vasorelaxant effect of fraction $\mathrm{F}(\mathrm{Fr}$. F) was stronger than those of the other major fractions obtained from the Ostericum citriodorum ethyl acetate extract (OCE). Endothelium-denuded aorta rings were pre-contracted with noradrenaline (NE) before the eight major fractions (Fr. A-H) $(1000 \mu \mathrm{g} / \mathrm{mL})$ were added. Values are means \pm standard error of the mean (SEM) $(n=6)$. Note: ${ }^{*} p<0.05,{ }^{* *} p<0.01$ each fraction compared with control (CON, incubation the vascular rings with $0.2 \% \mathrm{DMSO})$ group using two-way ANOVA.

\subsection{Isolation and Identification}

The molecular formula of the compound obtained from Fr. F was $\mathrm{C}_{12} \mathrm{H}_{12} \mathrm{O}_{6}$, electron ionization mass spectrometry (EI-MS) (positive) $\mathrm{m} / z: 279.085[\mathrm{M}+\mathrm{Na}]{ }^{+} .{ }^{1} \mathrm{H}-\mathrm{NMR}\left(\mathrm{CDCl}_{3}, 400 \mathrm{MHz}\right): \delta_{\mathrm{H}} 6.48(1 \mathrm{H}$, $\mathrm{s}, \mathrm{H6}), 5.96\left(2 \mathrm{H}, \mathrm{s}, \mathrm{H} 4^{\prime}\right), 4.52\left(1 \mathrm{H}, \mathrm{d}, J=7.2 \mathrm{~Hz}, \mathrm{H1} 1^{\prime}\right), 3.85\left(1 \mathrm{H}, \mathrm{m}, \mathrm{H2}{ }^{\prime}\right), 3.92\left(3 \mathrm{H}, \mathrm{s}, 2-\mathrm{OCH}_{3}\right), 3.85(3 \mathrm{H}, \mathrm{s}$, $\left.3-\mathrm{OCH}_{3}\right), 1.07\left(3 \mathrm{H}, \mathrm{d}, J=6.4 \mathrm{~Hz}, \mathrm{H}^{\prime}\right)$. In the heteronuclear multiple bond correlation ( $\left.\mathrm{HMBC}\right)$ spectrum, 
we found correlations between $\mathrm{H}^{\prime}$ and $\mathrm{C} 1 / \mathrm{C} 2 / \mathrm{C} 6$, and between $\mathrm{H} 2{ }^{\prime}$ and $\mathrm{C} 1$, indicating that $\mathrm{C} 1$ was connected to $\mathrm{C}^{\prime}$. The HMBC correlations between $\mathrm{H} 4^{\prime}$ and $\mathrm{C} 4 / \mathrm{C} 5$ suggested the connection of $\mathrm{C} 4, \mathrm{C} 5$, and the methylene dioxy groups of $\mathrm{C}^{\prime}$ ' via an oxygen bond, and the position of the methoxy group could be defined by the $\mathrm{HMBC}$ correlations between $\mathrm{H} 2-\mathrm{OCH}_{3}$ and $\mathrm{C} 2$, and between $\mathrm{H} 3-\mathrm{OCH}_{3}$ and $\mathrm{C}_{3}$. We found HMBC correlations between $\mathrm{H} 6$ and C1/C2/C4/C5. Thus, the planar structure was established (Figure 2A). Finally, we identified an erythro isomer between $\mathrm{H}^{\prime}$ and $\mathrm{H} 2^{\prime}$ caused by the coupling constant of $\mathrm{H}^{\prime}$ and $\mathrm{H}^{\prime}{ }^{\prime}, J=7.2 \mathrm{~Hz}$ (Figure 2B). Based on the above information, we determined that this compound is $1^{\prime}, 2^{\prime}$-erythro-1', $2^{\prime}$-dioxy-2,3-dimethoxy-4,5-methylenedioxy-1-propylbenzene.

The ${ }^{1} \mathrm{H}-\mathrm{NMR}$ data were basically consistent with those reported previously [17]; thus, the compound was identified as ${ }^{13} \mathrm{C}-\mathrm{NMR}\left(\mathrm{CDCl}_{3}, 100 \mathrm{MHz}\right)$ data: $\delta_{\mathrm{C}} 139.1(\mathrm{C} 3), 138.4(\mathrm{C} 4), 136.6(\mathrm{C} 5)$, 136.0 (C2), 126.1 (C1), $106.8(\mathrm{C} 6), 101.9\left(\mathrm{C}^{\prime}\right), 75.6\left(\mathrm{C}^{\prime}\right), 71.8\left(\mathrm{C}^{\prime}\right), 60.1\left(3-\mathrm{OCH}_{3}\right), 57.2\left(2-\mathrm{OCH}_{3}\right)$, $18.9\left(\mathrm{C}^{\prime}\right)$.

A<smiles>COc1c([C@H](O)[C@H](C)O)cc2c(c1OC)OCO2</smiles>

B

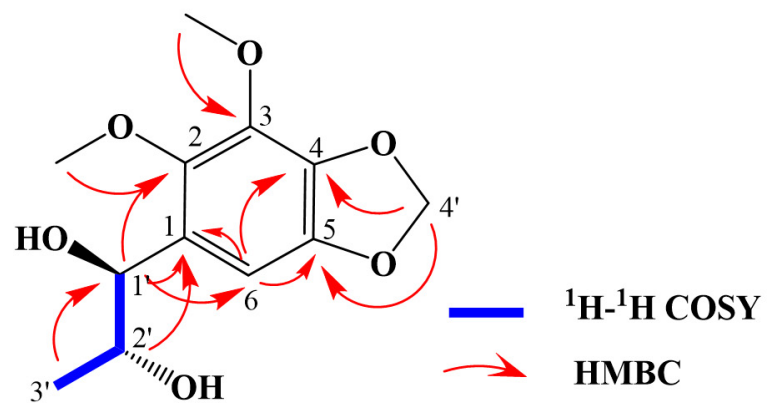

C

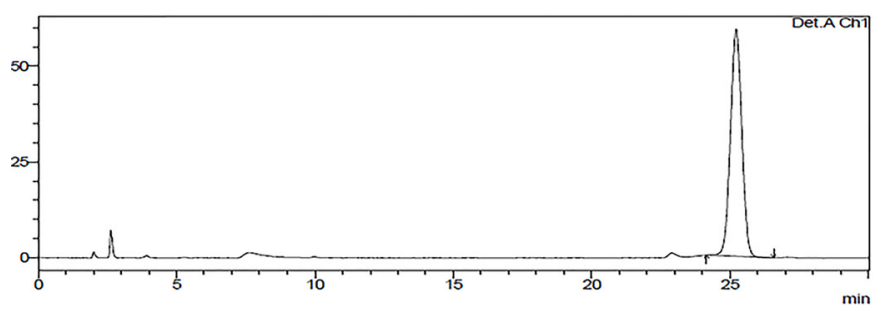

D

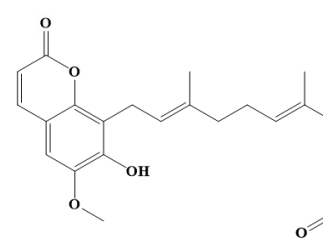

1

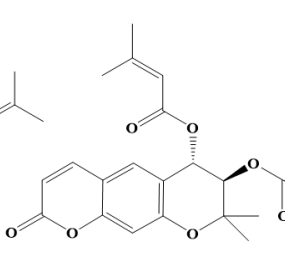

2

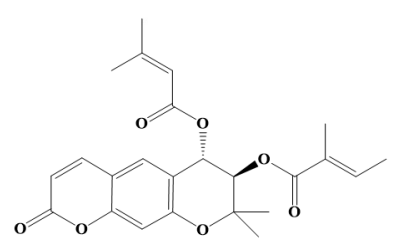

3

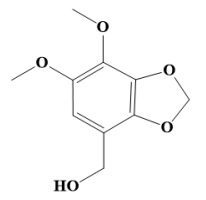

4

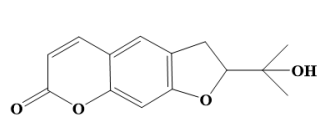

5

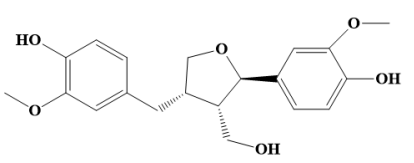

6

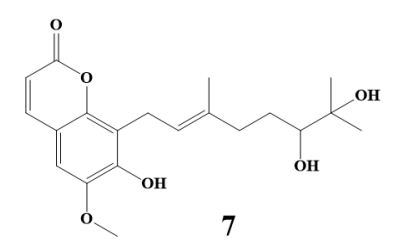

Figure 2. (A) Chemical structure, (B) key homonuclear chemical shift correlation spectroscopy $\left({ }^{1} \mathrm{H}-{ }^{1} \mathrm{H}\right.$ COSY), and heteronuclear multiple bond correlation (HMBC)correlations. (C) HPLC chromatogram analysis of isodillapiolglycol (IDG). (D) Chemical structures of compounds 1-7. 
By optimizing the chromatographic conditions, a Diamonsil $\mathrm{C}_{18}$ column $(5 \mu \mathrm{m}, 250 \times 4.6 \mathrm{~mm})$ was determined as the stationary phase. The mobile phase was 35\% methanol-water detected at 210 $\mathrm{nm}$. We detected that the purity of IDG was $97.0 \%$ and the content in O. citriodorum was $0.2955 \mathrm{mg} \cdot \mathrm{g}^{-1}$ (retention time $=25.05$ min; Figure 2C).

In addition to IDG being isolated from Fr. F, 8-(3,7-Dimethyl-octa-2,6-dienyl)-7-hydroxy-6-mehtoxychromen-2-one (1) was isolated from Fr. B. Decursidin (2) (CAS: 23027-48-7) and 9-angeloyloxy-10senecioyloxy-9,10-dihydroxanthyletin (3) were isolated from Fr. C. Additionally, 6,7-Dimethoxy-1,3benzodiox-ole-4-methanol (4) (CAS: 245421-64-1) was isolated from Fr. E. Nodakenetin (5) (CAS: 495-32-9) was isolated from Fr. F. Lariciresinol (6) (CAS: 27003-73-2) was isolated from Fr. G. Ostercitriodin A (7) was isolated from Fr. H (Figure 2D) (see Supplementary Materials for compound details). Among them, 8-(3,7-Dimethyl-octa-2,6-dienyl)-7-hydroxy-6-mehtoxy-chromen-2-one and ostercitriodin A are the newly isolated compounds.

\subsection{Vasorelaxant Effect of Isodillapiolglycol (IDG) vs. OCE at the Same Dose}

We investigated the relaxation effect of OCE or IDG on the vasoconstriction induced by NE stimulation. The endothelium-denuded aortic rings were pre-contracted with NE $(3 \mu \mathrm{M})$, and after this IDG $(200,400,800 \mu \mathrm{g} / \mathrm{mL})$ or OCE $(200,400,800 \mu \mathrm{g} / \mathrm{mL})$ was added. Within our designed dosage range, the vasorelaxant effect of IDG was significantly different from that of OCE $(p<0.01)$, which indicated the stronger vasodilation of IDG compared to that of OCE at the same dose (Figure 3).

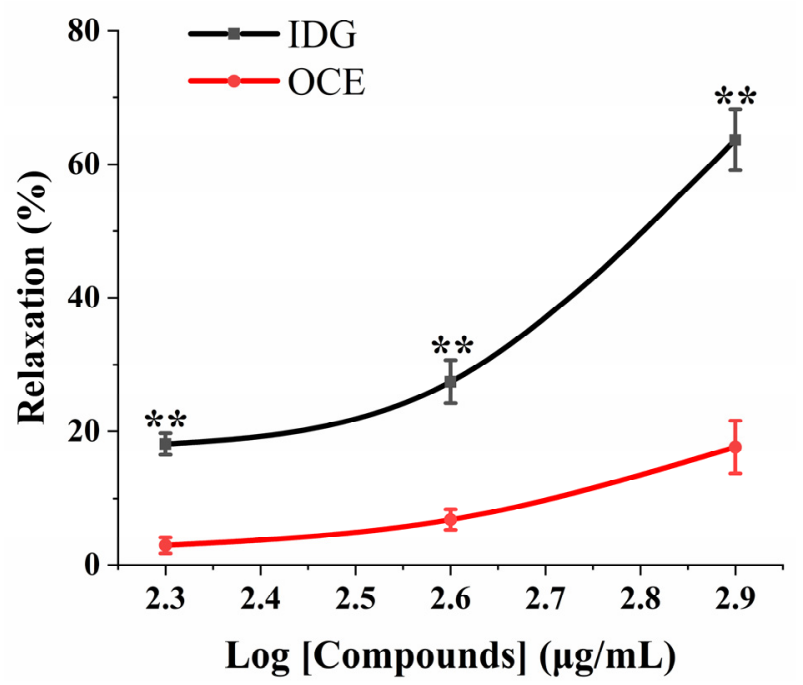

Figure 3. The vasodilatation induced by isodillapiolglycol (IDG) was stronger than that of OCE at the same dose. Endothelium-denuded aorta rings were pre-contracted with NE before the addition of IDG $(200,400,800 \mu \mathrm{g} / \mathrm{mL})$ or OCE $(200,400,800 \mu \mathrm{g} / \mathrm{mL})$. Values are means $\pm \operatorname{SEM}(n=6)$. Note: ${ }^{* *} p<0.01$ compared with the OCE group using two-way ANOVA.

\subsection{IDG Inhibition of Contraction Induced by NE or KCl in Endothelium-Intact or -Denuded Aortic Rings}

In these experiments, we investigated the vasorelaxant effects of IDG in aortic rings pre-contracted with $\mathrm{NE}(3 \mu \mathrm{M})$ or $\mathrm{KCl}(60 \mathrm{mM})$ in Krebs solution, and the half maximal effective concentration $\left(\mathrm{EC}_{50}\right)$ was calculated.

At concentrations ranging from 0.7 to $2.8 \mathrm{mM}$, IDG was observed to remarkably relax the aortic rings pre-contracted with $\mathrm{NE}$ or $\mathrm{KCl}$ in a dose-dependent manner, and the $\mathrm{EC}_{50}$ values of the relaxing effect of IDG for endothelium-intact arteries and endothelium-denuded arteries were $1.48 \pm 0.05$ and $1.54 \pm 0.1 \mathrm{mM}$ in NE-induced contraction and $1.59 \pm 0.04$ and $1.52 \pm 0.09 \mathrm{mM}$ in KCl-induced contraction, respectively. The data suggested that the vasodilatation of IDG in the endothelium-intact aortic rings was not significantly different from that found in the endothelium-denuded rings (Figure 4). 
On the other hand, the IDG $(0.7,1.4,2.8 \mathrm{mM})$ groups were statistically different compared to the sodium nitroprusside(SNP) group (" $p<0.01)$.

A
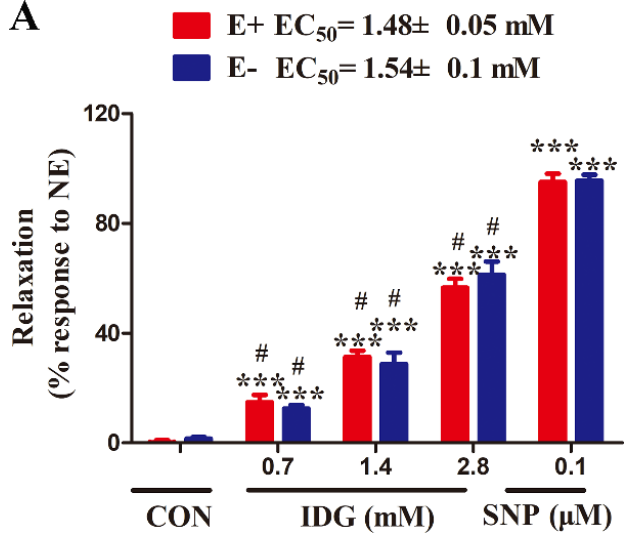

B

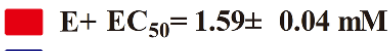

$\mathrm{E}-\mathrm{EC}_{50}=1.52 \pm 0.09 \mathrm{mM}$

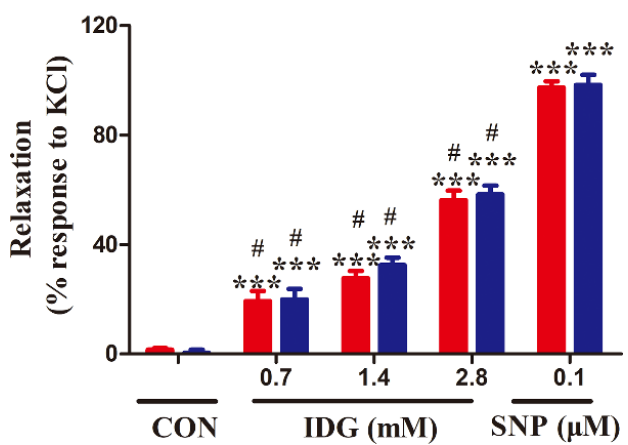

Figure 4. IDG directly caused relaxation in the vascular smooth muscle cells of aorta rings. Endothelium-intact $(\mathrm{E}+)$ or -denuded (E-) aorta rings were incubated with IDG $(0.7,1.4$, or 2.8 $\mathrm{mM})$ after being pre-contracted with $(\mathrm{A}) \mathrm{NE}(3 \mu \mathrm{M})$ or $($ B) potassium chloride $(\mathrm{KCl})(60 \mathrm{mM})$. Values are means $\pm \operatorname{SEM}(n=6)$. Relaxation for IDG was compared with control using two-way ANOVA. Note: ${ }^{* * *} p<0.001$ vs. CON $\left(0.2 \%\right.$ DMSO) group; ${ }^{\#} p<0.01$ vs. sodium nitroprusside (SNP) group.

\subsection{IDG Relaxed High $\mathrm{K}^{+}$Depolarized Aortic Rings Contracted by $\mathrm{CaCl}_{2}$}

In the $\mathrm{Ca}^{2+}$-free and high $\mathrm{K}^{+}$Krebs solution, the cumulative addition of $\mathrm{CaCl}_{2}(0.1-10 \mathrm{mM})$ induced a progressively increased vascular tension in aortic rings [18]. Pre-incubation with IDG $(0.7,1.4$, or $2.8 \mathrm{mM})$ significantly inhibited the concentration-response contraction of $\mathrm{CaCl}_{2}(0.1-10$ $\mathrm{mM})$; compared with the control $(\mathrm{CON})$ group, the maximum contraction was $64.48 \% \pm 13.61 \%$, $56.38 \% \pm 5.19 \%$, and $53.73 \% \pm 2.67 \%$, respectively (Figure 5).

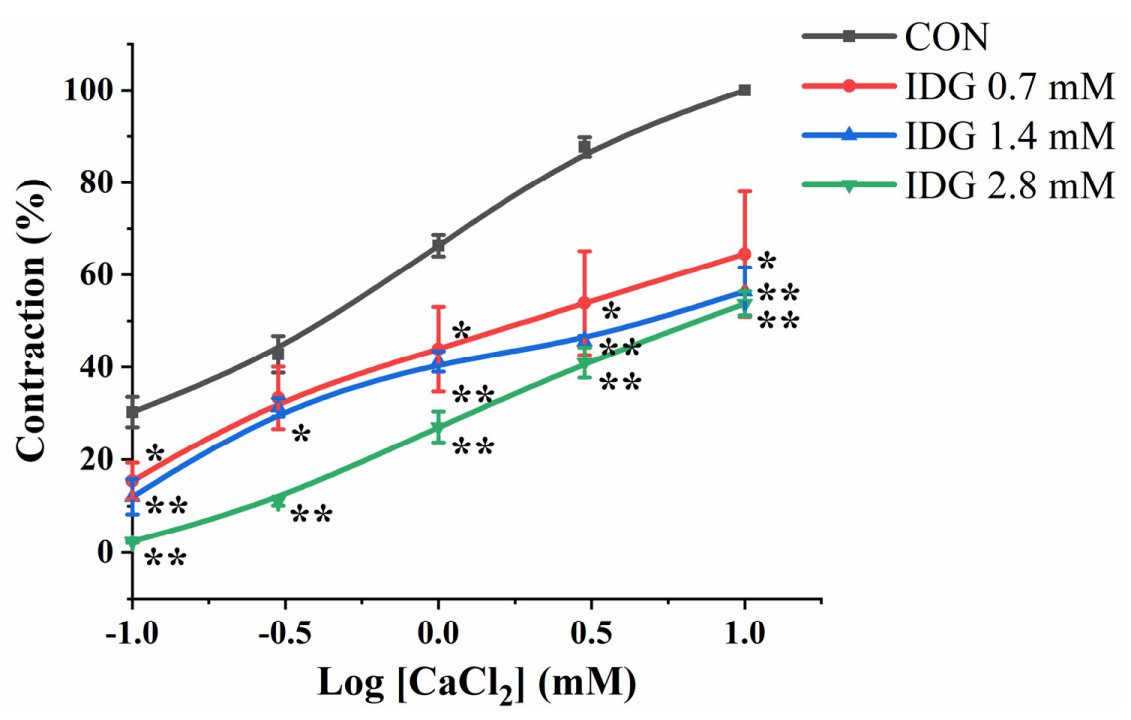

Figure 5. $\mathrm{CaCl}_{2}$-induced contractions of endothelium-denuded aortic rings pre-incubated in high $\mathrm{K}^{+}$ and $\mathrm{Ca}^{2+}$-free Krebs solution under conditions of pre-incubation with DMSO (negative control) or IDG $(0.7,1.4,2.8 \mathrm{mM})$. Y-axis, \% contraction compared to the contraction achieved with the highest $\mathrm{Ca}^{2+}$ concentration $(10 \mathrm{mM})$ during the initial run without IDG in endothelium-denuded aortic rings. Values are mean \pm SEM $(n=6)$. The contraction was determined using non-linear regression and a repeated-measures two-way ANOVA to compare curves. Statistically significant difference are * $p<$ $0.05,{ }^{* *} p<0.01,{ }^{* * *} p<0.001$ vs. CON group. 


\subsection{Verapamil (VER) Inhibition of Vasorelaxant Effects of IDG in Aortic Rings Pre-Contracted with NE}

The L-type $\mathrm{Ca}^{2+}$ channel (LTCC) is a major pathway for $\mathrm{Ca}^{2+}$ entry in most blood vessels, which can be inhibited by VER $[19,20]$. Pretreatment of endothelium-denuded aortic rings with VER significantly diminished NE-induced vasoconstriction (Figure 6A), after which IDG was added, eliciting vasodilatation. In the presence or absence of VER $(10 \mu \mathrm{M})$, the maximal vasorelaxant effects were $24.51 \% \pm 2.22 \%$ and $63.85 \% \pm 6.09 \%$, respectively. We suggest that IDG still had a vasodilating effect when the L-type $\mathrm{Ca}^{2+}$ channel was blocked; this vasorelaxant effect was significantly lower than that in the control group without VER, indicating that the vasodilatation of IDG was blocked by VER (Figure 6B).
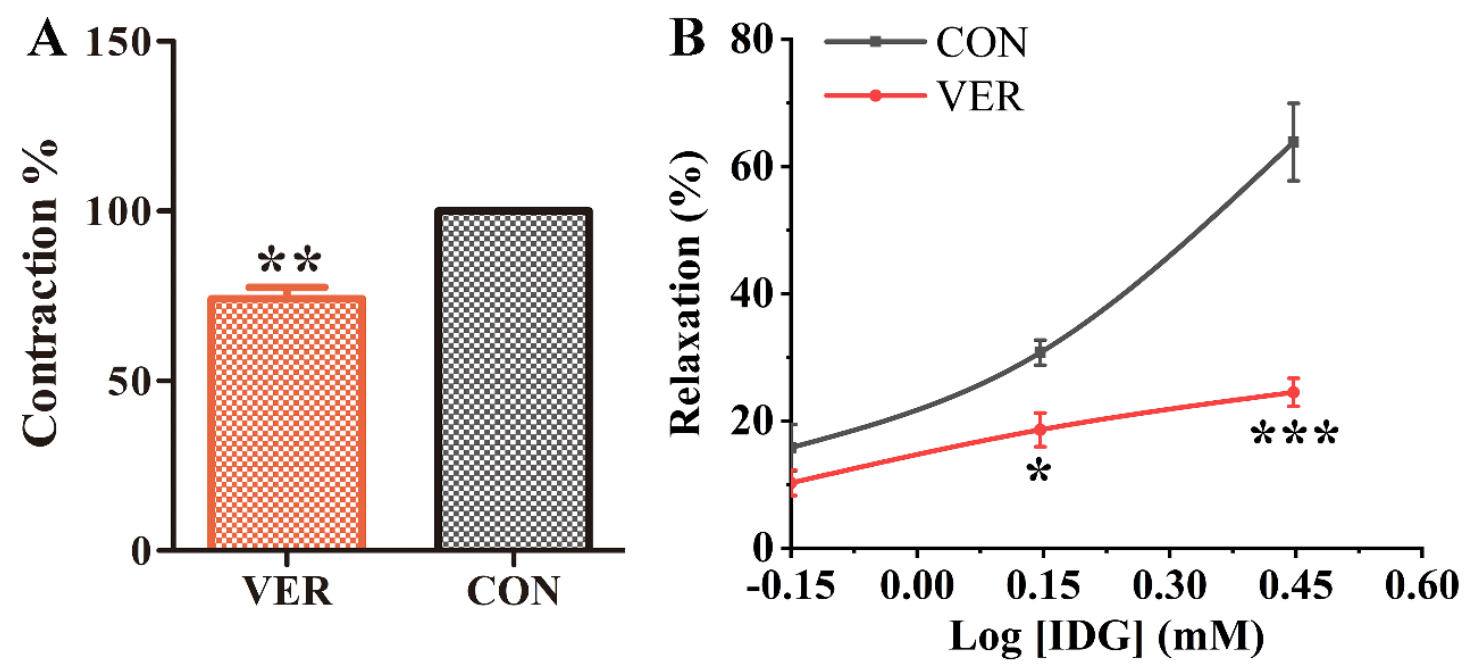

Figure 6. Effect of verapamil (VER) on the vascular relaxation of IDG. (A) In endothelium-denuded aortic rings contracted with NE before pre-incubation with or without VER $(10 \mu \mathrm{M})$, the maximum contraction of the CON group caused by NE $(10 \mathrm{mM})$ was recorded as $100 \%$. (B) Vasoconstriction occurred when IDG $(0.7,1.4$, or $2.8 \mathrm{mM})$ was added. Statistical analysis was performed using two-way ANOVA; ${ }^{*} p<0.05,{ }^{* * *} p<0.001$ vs. CON group.

\subsection{Tetraethylammonium-Chloride Inhibition of Vasorelaxation of IDG in NE Pre-Contracted Aortic Rings}

In NE-induced vasoconstriction, pretreatment with tetraethylammonium chloride (TEA; $1 \mathrm{mM})$, a blocker of the $\mathrm{Ca}^{2+}$-activated $\mathrm{K}^{+}$channel $\left(\mathrm{K}_{\mathrm{Ca}}\right)$, reduced the vasodilatory effects of IDG. The maximum contraction $\left(\mathrm{E}_{\max }\right)$ of IDG was $23.76 \% \pm 3.07 \%\left(\mathrm{EC}_{50}=1.23 \pm 0.15 \mathrm{mM}\right)$ at a dose of $2.8 \mathrm{mM}$ vs. the CON group's value of $60.10 \% \pm 4.57 \%$. However, $\mathrm{BaCl}_{2}$, a blocker of the inward-rectifier potassium ion channel $\left(\mathrm{K}_{\mathrm{ir}}\right)$, did not affect the vasodilatory effects of IDG. In the presence and absence of $\mathrm{BaCl}_{2}$ $(10 \mu \mathrm{M})$, the $\mathrm{E}_{\max }$ values with IDG preincubation $(2.8 \mathrm{mM})$ were $57.9 \% \pm 3.19 \%\left(\mathrm{EC}_{50}=1.55 \pm 0.04 \mathrm{mM}\right)$ and $60.10 \% \pm 4.57 \%\left(\mathrm{EC}_{50}=1.47 \pm 0.01 \mathrm{mM}\right)$, respectively (Figure 7$)$. 


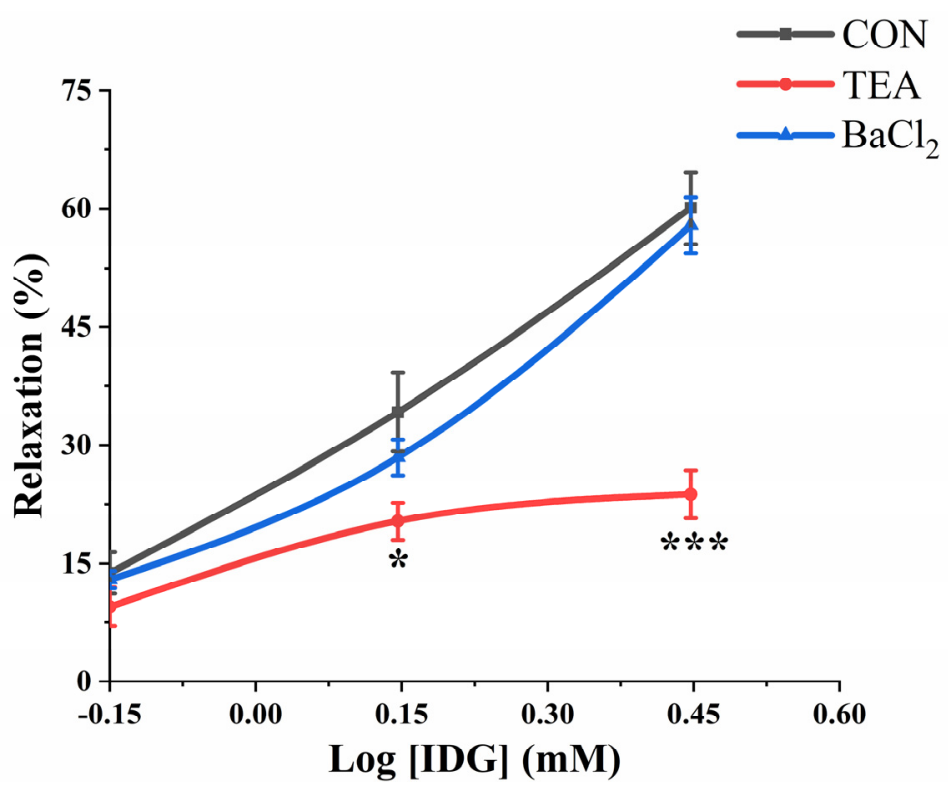

Figure 7. Evaluation of the IDG vasodilatation mechanism associated with $\mathrm{K}^{+}$channels. Vasorelaxant effects of IDG $(0.7,1.4$, or $2.8 \mathrm{mM})$ in NE-pre-contracted endothelium-denuded aorta rings with or without tetraethylammonium (TEA, $1 \mathrm{mM}$ ), a blocker of the $\mathrm{Ca}^{2+}$-activated $\mathrm{K}^{+}$channel, or $\mathrm{BaCl}_{2}$ $(10 \mu \mathrm{M})$, a blocker of the inward-rectifier $\mathrm{K}^{+}$channel. The half maximal effective concentration $\left(\mathrm{EC}_{50}\right)$ was determined using non-linear regression and a repeated-measures two-way ANOVA to compare curves; $n=6$. Note: ${ }^{*} p<0.05$, ${ }^{* * *} p<0.001$ vs. CON.

\subsection{IDG Reduced the Increase in $\left[\mathrm{Ca}^{2+}\right]_{\text {in }}$ Stimulated by $\mathrm{NE}$ or $\mathrm{KCl}$}

We used a fluo-3/AM molecular probe to observe the change of $\left[\mathrm{Ca}^{2+}\right]_{\text {in }}$ fluorescence intensity in VSMCs. In the first instance, the increase of $\left[\mathrm{Ca}^{2+}\right]_{\text {in }}$ fluorescence intensity generated by NE in VSMCs pre-treated with IDG was significantly lower $(p<0.05)$ in $\mathrm{Ca}^{2+}$-free Krebs solution than that observed in the control (Figure 8). Then, the addition of $\mathrm{CaCl}_{2}(2.5 \mathrm{mM})$ in VSMCs of these groups showed a significant elevation in the $\left[\mathrm{Ca}^{2+}\right]_{\text {in }}$ fluorescence intensity; however, compared with $\mathrm{CON}$ group, the $\left[\mathrm{Ca}^{2+}\right]_{\text {in }}$ fluorescence intensity in VSMCs pre-treated with IDG $(0.7,1.4$, and $2.8 \mathrm{mM})$ produced decreases of $11.93 \%, 24.23 \%$ and $65.95 \%$, respectively (Figure $8 \mathrm{~B}$ ). In another group, a similar phenomenon was observed when VSMCs were stimulated by $\mathrm{KCl}(100 \mathrm{mM})$ in Krebs solution, with the $\left[\mathrm{Ca}^{2+}\right]_{\text {in }}$ fluorescence intensities decreasing by $13.84 \%, 34.82 \%, 52.58 \%$, and $43.18 \%$ compared with the CON group after the cells were preincubated with IDG $(0.7,1.4$, and $2.8 \mathrm{mM})$ and SNP $(0.1 \mu \mathrm{M})$, respectively (Figure 8). 


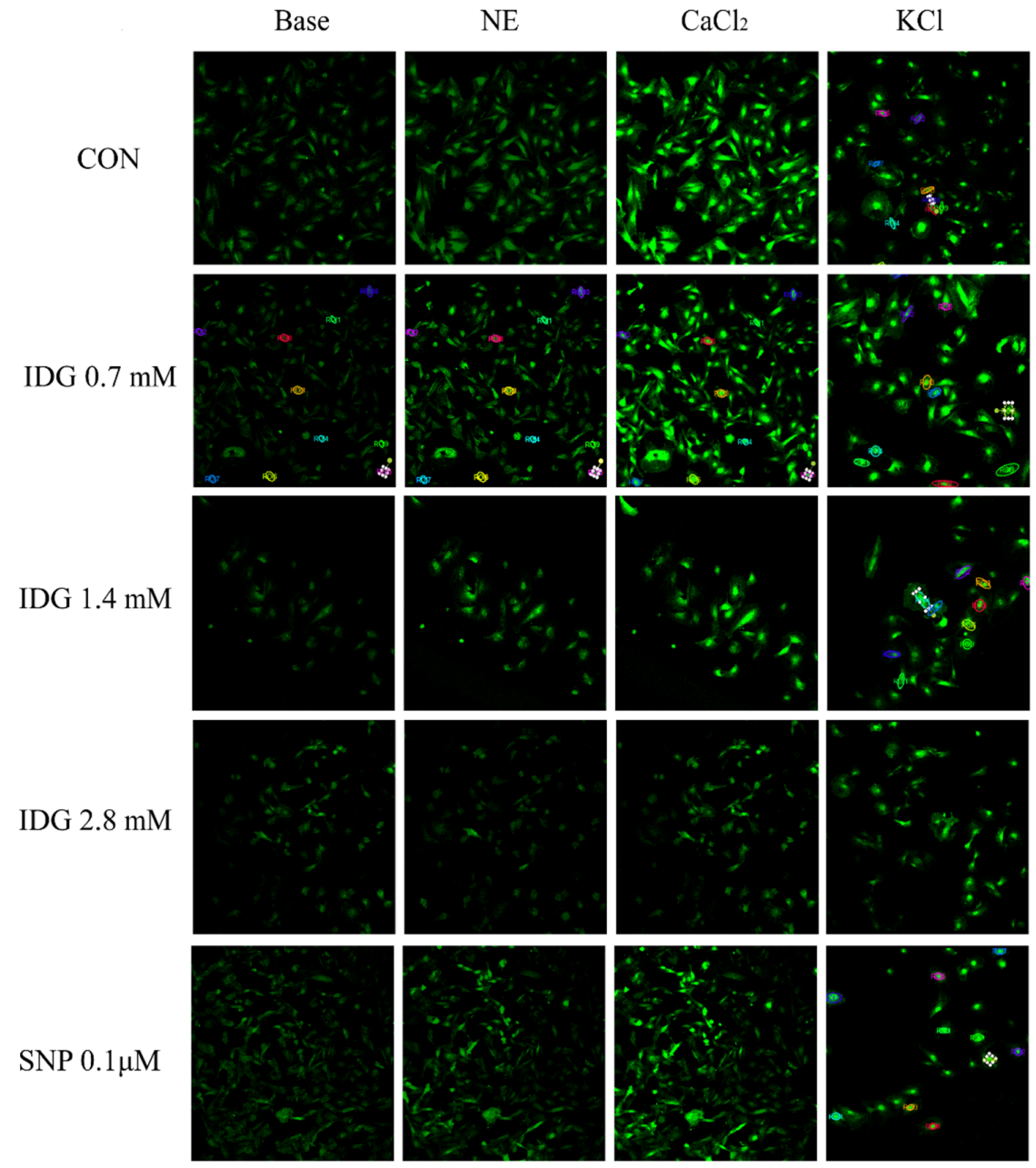

(A)

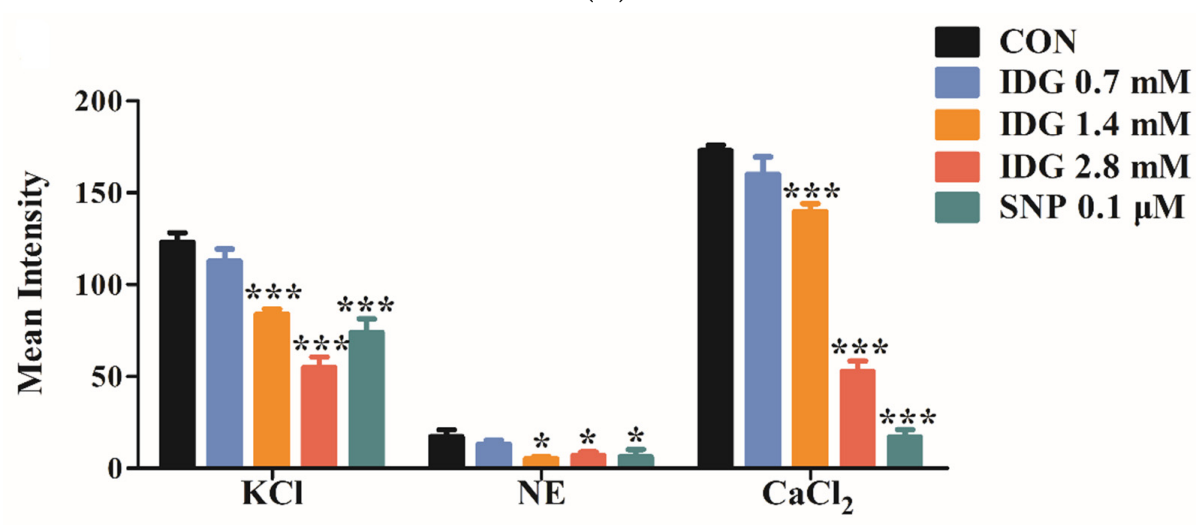

(B)

Figure 8. Relaxant effect of IDG $(0.7,1.4$, and $2.8 \mathrm{mM})$ on vascular smooth muscle cells (VSMCs) contracted with $\mathrm{NE}(10 \mu \mathrm{M})$ or $\mathrm{KCl}(100 \mathrm{mM})$. (A) The change in fluorescence intensities represent the change in $\left[\mathrm{Ca}^{2+}\right]_{\text {in }}$ levels. Original fluorescence images $(40 \times)$. (B) The effects of $\operatorname{IDG}(0.7,1.4$, and 2.8 $\mathrm{mM}$ ) reduced the increase in intracellular fluorescence intensity in VSMCs due to $\mathrm{KCl}(100 \mathrm{mM})$ in Krebs solution, $\mathrm{NE}(10 \mu \mathrm{M})$ in $\mathrm{Ca}^{2+}$-free Krebs solution, or the addition of $\mathrm{CaCl}_{2}(2.5 \mathrm{mM})$ to provide $\mathrm{Ca}^{2+}$. Values are means \pm SEM $(n=6)$. Statistical analysis was performed using two-way ANOVA. Note: ${ }^{*} p<0.05,{ }^{* * *} p<0.001$ compared with CON group. 


\section{Discussion}

IDG is one of the main major constituents of $O$. citriodorum. This study demonstrated that IDG showed a vasorelaxant effect in isolated rat aortic rings, which occurred in a dose-dependent and endothelium-independent manner. More importantly, we determined the mechanism of IDG vasorelaxation through reducing $\left[\mathrm{Ca}^{2+}\right]_{\text {in }}$ in VSMCs and found that it was probably related to ROCC, VDCC, and $\mathrm{K}_{\mathrm{Ca}}$.

The OCE was subjected to a silica gel column using gradient mixtures of chloroform-methanol as eluents to obtain eight major fractions (Fr. A-Fr. H). We investigated the vasodilating effect of these fractions and found that Fr. F had the strongest vasodilatory effect. Then, we further separated and purified these fractions. Using Sephadex LH-20 columns or ostade-cylsilane (ODS)columns, we obtained IDG and 7 other compounds, among which 8-(3,7-Dimethyl-octa-2,6-dienyl)-7-hydroxy-6-mehtoxy-chromen-2-one and ostercitriodin A are the newly isolated compounds. In a preliminary experiment, IDG, which was obtained from Fr. F, showed a stronger vasodilatory effect than other compounds. We then investigated the vasorelaxant effects of IDG in rat aortic rings and the possible mechanisms of this action.

It is known that NE binds to the serpentine receptor and activates phospholipase $\mathrm{C}$ through G-protein, which generates inositol-1,4,5- triphosphate (IP3) [21]. The binding of IP3 to receptors on the $\mathrm{SR}$ results in the release of $\mathrm{Ca}^{2+}$ into the cytoplasm, and activates ROCC on the cell membrane, leading to extracellular $\mathrm{Ca}^{2+}$ influx [22-24]. A high concentration of $\mathrm{KCl}$ induced cell membrane depolarization and activated VDCC [25]. Our findings showed that IDG $(0.7,1.4$, and $2.8 \mathrm{mM})$ dose-dependently relaxed $\mathrm{NE}$ - or $\mathrm{KCl}$-induced contraction in endothelium-intact or -denuded aortic rings, and also inhibited $\mathrm{CaCl}_{2}$-induced contraction in high $\mathrm{K}^{+}$depolarized aortic rings. The results show that IDG exerted vasodilating effects in a dose-dependent and endothelial-independent manner, and possibly also through inhibiting extracellular $\mathrm{Ca}^{2+}$ influx. On the other hand, the vasoconstriction stimulated by NE could still be relaxed by IDG, whether or not aortic rings were pre-incubated with VER. However, the group with VER was weaker than CON group, which means that (1) IDG may play a role in inhibiting the release of internal $\mathrm{Ca}^{2+}$ and that (2) the vasodilatory effect of IDG was related to the L-type $\mathrm{Ca}^{2+}$ channel.

$\mathrm{Ca}^{2+}$ is a critical factor in excitation-contraction coupling in VSMCs [22,23]. To prove that IDG relaxed the aortic rings by regulating $\left[\mathrm{Ca}^{2+}\right]_{\text {in }}$ in VSMCs, a molecular fluo-3/AM probe was used to measure real-time changes in $\left[\mathrm{Ca}^{2+}\right]_{\text {in }}$ induced by $\mathrm{KCl}$ or $\mathrm{NE}$. In the $\mathrm{Ca}^{2+}$-free Krebs solution, the average fluorescence intensity of VSMCs was detected after stimulation by NE and subsequent supplementation of $\mathrm{CaCl}_{2}$. The average mean fluorescence intensities of different doses of IDG groups significantly decreased compared with the CON group, indicating that IDG inhibited the extracellular $\mathrm{Ca}^{2+}$ influx and intracellular $\mathrm{Ca}^{2+}$ release through ROCC. Different concentrations of IDG attenuated the increase in $\left[\mathrm{Ca}^{2+}\right]_{\text {in }}$ fluorescence intensity induced by $\mathrm{KCl}$, which suggests that IDG could act on VDCC, inhibiting $\mathrm{Ca}^{2+}$ influx. Therefore, these findings demonstrated that IDG inhibits the $\mathrm{KCl}$ - or NE-induced increases in $\left[\mathrm{Ca}^{2+}\right]_{\text {in }}$ in VSMCs, possibly through VDCC and ROCC.

Besides $\mathrm{Ca}^{2+}$ channels, $\mathrm{K}^{+}$channels also play an important role in vasodilation [26,27]. Activation of $\mathrm{K}^{+}$channels in VSMCs normally hyperpolarizes the cell membrane due to an efflux of $\mathrm{K}^{+}$, which suppresses VSMC contraction [28,29]. Our experiment demonstrated that the effects of IDG in NE-contracted rings were attenuated by TEA but not $\mathrm{BaCl}_{2}$, which manifested in the vasodilatory effects related to $\mathrm{K}_{\mathrm{Ca}}$.

Taken together, our findings indicated that IDG caused endothelium-independent vasorelaxation in rat aortic rings, and that the vasorelaxant activity was related to ROCC, VDCC, or K $\mathrm{Ca}_{\mathrm{Ca}}$ (Figure 9). Further studies are needed to investigate the precise mechanisms of its action. 

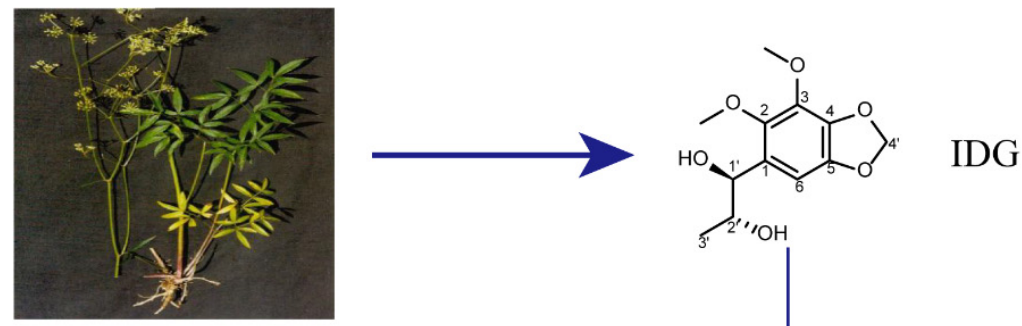

O. citriodorum

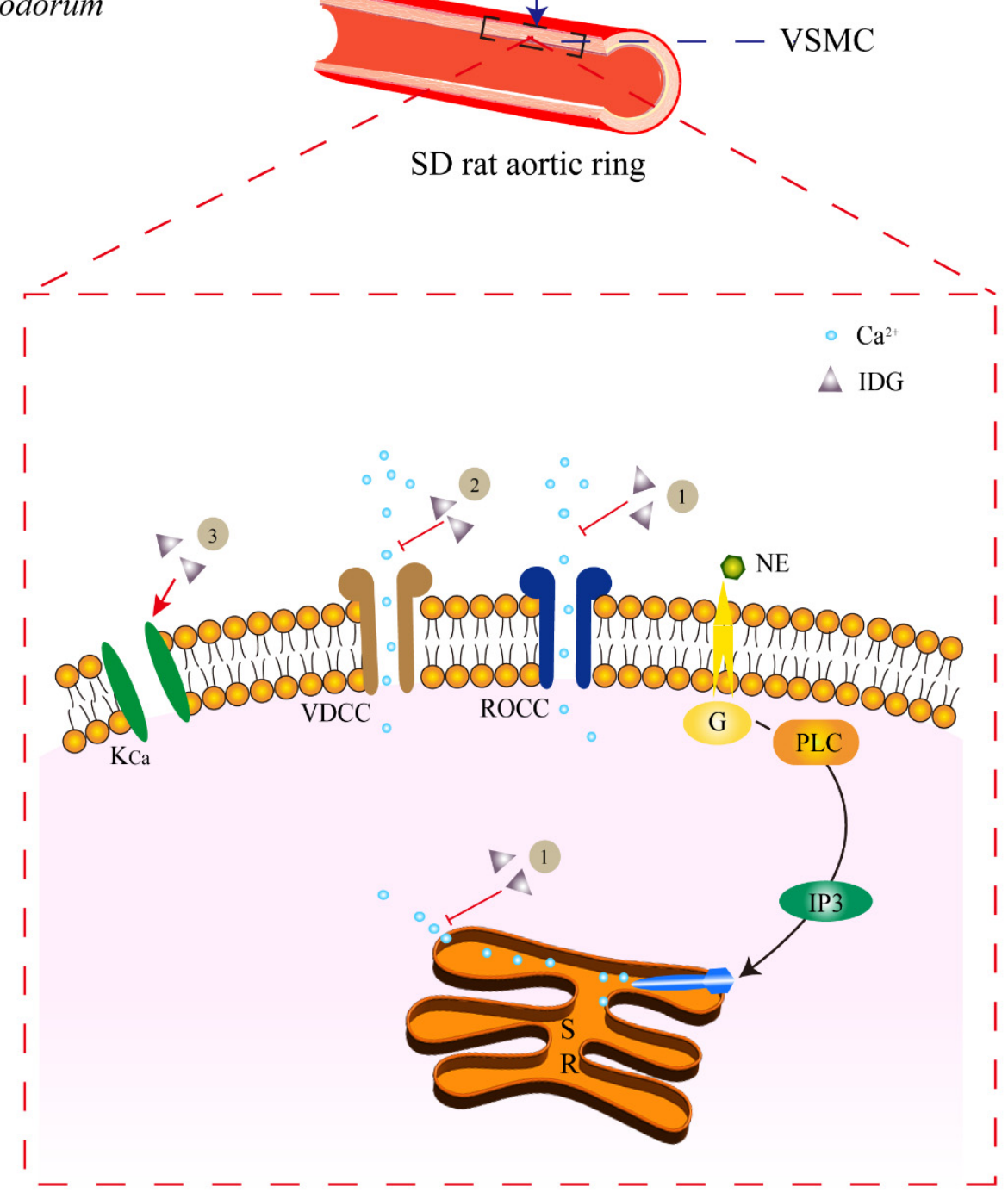

Figure 9. The role of IDG in relaxing vascular smooth muscle cells could be related to the following pathways: (1) the vasorelaxant effects of IDG caused by inhibiting extracellular $\mathrm{Ca}^{2+}$ influx and intracellular $\mathrm{Ca}^{2+}$ release through the receptor-operated $\mathrm{Ca}^{2+}$ channel (ROCC); (2) IDG-inhibited extracellular $\mathrm{Ca}^{2+}$ influx through the voltage-dependent $\mathrm{Ca}^{2+}$ channel (VDCC); (3) IDG may activate the $\mathrm{K}_{\mathrm{Ca}}$ channel.

A limitation of this study is the lack of research about IDG absorption in vivo. It is important to note that an ex vivo model of isolated aortic rings is a useful system for testing the vasoreactivity potency of compounds, but does not allow comprehensive evaluation of the potential pharmacological activities or functions [30]. In terms of the efficacy or the future therapeutic applications of IDG, systematically conducting in vivo or in vitro studies is necessary.

In our previous research [13], we found that isoapiole, one of the main ingredients isolated from the petroleum ether extract of $O$. citriodorum, relaxed the aortic rings in an endothelium-dependent manner 
via the NO pathway. However, the vasorelaxant effects of IDG worked in an endothelium-independent manner by reducing $\left[\mathrm{Ca}^{2+}\right]_{\text {in }}$ in VSMCs. Thus, one of the more significant findings to emerge from this study is that the vasorelaxant effects of $O$. citriodorum are possibly derived from its variety of components, which exert their effects on disease by binding multiple targets, resulting in synergistic therapeutic activities.

Therapeutic agents sourced from herbal medicines show potential for the treatment of AP [31]. As a traditional herbal medicine, O. citriodorum has good clinical value for treatment of AP or coronary disease, but there are a few studies on this subject. To the best of our knowledge, this study is the first to analyze the OCE and its eight compounds, which included two newly isolated compounds. On the other hand, we have investigated the vasodilation effect of the 8 fractions (Figure 1). Both of the compounds showed medicinal effects, meaning that $O$. citriodorum has great potential for treating AP and other cardiovascular diseases. However, our experiment focuses on the research on IDG, which was isolated from Fr. F fractions, although this will help us to understand the role of O. citriodorum in treating AP. However, it is necessary to continue research on the vasodilation effect of the other components in O. citriodorum and explore the laws of their interaction. Not only could this explain the mechanism of $O$. citriodorum in treatment for AP and other diseases, but could also provide valuable leads for the development of natural drugs that are useful in the treatment of cardiovascular diseases.

\section{Materials and Methods}

\subsection{Animals}

Specific pathogen-free (SPF) grade healthy male Sprague-Dawley (SD) rats weighing $250 \pm 30$ $\mathrm{g}$ each were obtained from the Experimental Animal Center of Guangzhou University of Chinese Medicine (No: SCXK-2013-0020). The animals were caged under standard laboratory conditions, at a constant temperature $\left(22 \pm 1{ }^{\circ} \mathrm{C}\right)$ and under a $12 \mathrm{~h}$ light/dark cycle, with free access to food and water. The rats were also allowed to acclimatize to the animal facility for at least seven days before the start of the experiments. The animal care and use protocol was reviewed and approved by the Ethics Committee of Guangzhou University of Chinese Medicine (Date 6 March 2018, Approval number: 20180306022).

\subsection{Drugs and Reagents}

O. citriodorum was purchased from the Chinese medicine port of Guangxi Yulin, and was authenticated by Professor Haibo Huang at Guangzhou University of Chinese Medicine. Herbarium voucher specimens of $O$. citriodorum (XZ 08) were prepared and deposited at the Research and Development Center for new Chinese drugs, Guangzhou University of Chinese Medicine. NE, acetylcholine (Ach), DMSO, EGTA, TEA, and bovine serum albumin (BSA) were purchased from Sigma-Aldrich (St. Louis, MO, USA). Verapamil hydrochloride injection was purchased from Shanghai Harvest Pharmaceutical Co., Ltd. (Shanghai, China, 43141201). Sodium nitroprusside for injection was obtained from Hunan Koren Pharmaceutical Co., Ltd. (Hunan, China, B15070204). Dulbecco's modified Eagle's medium (DMEM) and fetal bovine serum (FBS) were obtained from Hyclone (Logan, UT, USA). Fluo-3-AM was acquired from Invitrogen (Carlsbad, CA, USA).

\subsection{Cells}

A7r5 cells were obtained from Shanghai Institute for Biological Sciences. The bath concentration of DMSO did not exceed $0.3 \%$, which had no effect, per se, on the basal tonus of the preparations or on the agonist-mediated contraction or relaxation. The cell was cultured in Dulbecco's modified Eagle's medium containing $10 \%$ fetal bovine serum (FBS) at $37^{\circ} \mathrm{C}$ with $5 \% \mathrm{CO}_{2}$, and the medium was changed every 2 or 3 days. 


\subsection{Preparation of SD Rat Thoracic Aortic Rings}

Sprague-Dawley rats were narcotized using 10\% chloral hydrate, and the abdominal aorta was bled to death. The thoracic aorta was dissociated and immediately transferred to ice-cold modified Krebs solution, then segmented into rings measuring approximately $3-4 \mathrm{~mm}$ each after clearing perivascular fat and adhesive connective tissues. Rings were mounted with two wire hooks: one of the hooks was fixed at the bottom of the organ bath, whereas the other was connected via a micrometric manipulator to a force displacement transducer for measurement of the isometric force. They were suspended in organ baths containing $15 \mathrm{~mL}$ Krebs solution filled with a continuous gas mixture of $95 \% \mathrm{O}_{2}$ and $5 \% \mathrm{CO}_{2}$ at $37^{\circ} \mathrm{C}$. The altered responses of the thoracic aorta tension were recorded with a ML870 Power Lab Biological Signal Collection System (AD Instruments, Castle Hill, NSW, Australia). The resting tension was gradually adjusted to $1.5 \mathrm{~g}$ over $1 \mathrm{~h}$, and equilibrated for $30 \mathrm{~min}$. The Krebs solution was replaced every $20 \mathrm{~min}$.

\subsection{Vasorelaxant Effects of Major Fractions in Aortic Rings Contracted by NE}

In the first experiment, $\mathrm{NE}(3 \mu \mathrm{M})$ was used to induce a steady contraction in denuded endothelium aortic rings, and 8 major fractions (Fr. A-H) were added individually. The changes in vascular tension were recorded, and the vasodilation rate (\%) was calculated as:

Relaxation $(\%)=($ maximal contraction by NE - tension at the corresponding time after incubation with tested compounds)/(maximal contraction by NE - basal

tension) $\times 100 \%$.

\subsection{Extraction of Compounds and Structural Analysis}

Air-dried and powdered O. citriodorum $(9 \mathrm{~kg})$ was extracted with $80 \%$ ethanol $(45 \mathrm{~L})$ three times under heating reflux. The ethanol extract was concentrated under a vacuum to yield a crude extract, which was suspended in water and then extracted successively with petroleum ether and ethyl acetate. The ethyl acetate extract fraction ( $153.7 \mathrm{~g}$ ) was subjected to a silica gel column using gradient mixtures of chloroform-methanol as eluents to obtain the 8 major fractions (Fr. A-H). Then, in Sephadex LH-20 columns (chloroform-methanol, 1:1, v/v), Fr. B (12.07g) was further subjected to an ODS column using $\mathrm{MeOH}-\mathrm{H}_{2} \mathrm{O}(7: 3, \mathrm{v} / \mathrm{v})$ as an eluent to produce compound $\mathbf{1}(13 \mathrm{mg})$. Fr. C (3.39 g) was further subjected to an ODS column using $\mathrm{MeOH}-\mathrm{H}_{2} \mathrm{O}(75: 25, v / v)$ as an eluent to produce compounds 2 $(5.2 \mathrm{mg})$ and $3(3.7 \mathrm{mg})$. Fr. E (1.01 g) was separated using a Sephadex $\mathrm{LH}-20$ column $\left(\mathrm{CHCl}_{3}-\mathrm{MeOH}\right.$, $50: 50, v / v)$ to obtain three subfractions (Fr. E1-Fr. E3). Fr. E3 was further subjected to an ODS column using $\mathrm{MeOH}-\mathrm{H} 2 \mathrm{O}(7: 3, v / v)$ as an eluent to produce compound $4(7.8 \mathrm{mg})$. Fr. F $(8.27 \mathrm{~g})$ was separated using a Sephadex LH-20 column $\left(\mathrm{CHCl}_{3}-\mathrm{MeOH}, 50: 50, v / v\right)$ to obtain seven subfractions (Fr. F1-F7). Fr. F6 was further purified by reversed-phase preparative HPLC using $\mathrm{MeOH}-\mathrm{H}_{2} \mathrm{O}$ (3:7) as the mobile phase to yield $5(22 \mathrm{mg})$ and $\mathbf{6}(7.5 \mathrm{mg})$. Fr. G (7.53 g) was separated using a Sephadex LH-20 column $\left(\mathrm{CHCl}_{3}-\mathrm{MeOH}, 50: 50, v / v\right)$ to obtain five subfractions (Fr. G1-G7). Fr. G3 was separated by a Sephadex $\mathrm{LH}-20$ column ( $\mathrm{MeOH}-\mathrm{CHCl}_{3}, 5: 95$ to 95:5, v/v) to produce Fr. G3a-G3c. Fr. G3c was further subjected to an ODS column using $\mathrm{MeOH}-\mathrm{H}_{2} \mathrm{O}(3: 7, v / v)$ as an eluent to produce compound 7 (15 mg). Fr. $\mathrm{H}$ (5.16 g) was separated using a Sephadex $\mathrm{LH}-20$ column $\left(\mathrm{CHCl}_{3}-\mathrm{MeOH}, 50: 50, v / v\right)$ to produce five subfractions (Fr. H1-H5). Fr. H3 was separated using a Sephadex $\mathrm{LH}-20$ column $\left(\mathrm{MeOH}-\mathrm{CHCl}_{3}\right.$, $5: 95$ to $95: 5, v / v)$ to produce Fr. H3a-H3c. Fr. H3c was further subjected to an ODS column using $\mathrm{MeOH}-\mathrm{H}_{2} \mathrm{O}(1: 1, v / v)$ as an eluent to produce compound $8(8.2 \mathrm{mg})$. The structures were established using a combination of spectroscopic methods, and the data were compared with those reported in the literature. 


\subsection{Vasorelaxant Effects of IDG in Aortic Rings Contracted by NE or $\mathrm{KCl}$}

To investigate the vasorelaxant activity, $\mathrm{NE}(3 \mu \mathrm{M})$ or $\mathrm{KCl}(60 \mathrm{mM})$ was used to induce a steady contraction in aortic rings with an intact or denuded endothelium, and IDG at three different doses (0.7, 1.4 , or $2.8 \mathrm{mM})$ or SNP (100 $\mathrm{nM})$ was added for $10 \mathrm{~min}$ to confirm inhibitory activities. The changes in vascular tension were recorded, and the vasodilation rate (\%) was calculated as:

Relaxation $(\%)=($ the maximal contraction by NE $($ or $\mathrm{KCl})-$ tension at the corresponding time after incubation with the tested compounds)/(maximal contraction by $\mathrm{NE}($ or $\mathrm{KCl})-$ basal tension) $\times 100 \%$.

To investigate the role of extracellular $\mathrm{Ca}^{2+}$ influx, LTCC, in the $\mathrm{K}^{+}$channel in IDG-induced vasorelaxation, the following drugs or inhibitors were used: $\mathrm{CaCl}_{2}$, VER $(10 \mathrm{mM})$, a blocker of LTCC; TEA $(1 \mathrm{mM})$, a blocker of $\mathrm{K}_{\mathrm{Ca}} ; \mathrm{BaCl}_{2}(10 \mu \mathrm{M})$, a blocker of $\mathrm{K}_{\mathrm{ir}}$. The endothelium-denuded aortic rings were pre-incubated with each blocker before contraction by NE $(3 \mu \mathrm{M})$.

\subsection{Effects of IDG on $\left[\mathrm{Ca}^{2+}\right]_{\text {in }}$ in VSMCs}

VSMCs were plated on dishes and loaded with Fluo-3/AM $10 \mu \mathrm{mol} / \mathrm{L}$ for $45 \mathrm{~min}$ in Krebs or $\mathrm{Ca}^{2+}$-free Krebs solution. VSMCs were then washed thrice with Krebs solution at $37^{\circ} \mathrm{C}$ to remove the extracellular excess of dye. Excitation and emission wavelengths were set to 488 and $525 \mathrm{~nm}$, respectively. The effects of IDG $(0.7,1.4,2.8 \mathrm{mM})$ on $\mathrm{KCl}(100 \mathrm{mM})$-induced fluorescence emission were evaluated in Krebs solution, and the effects of IDG on NE $(10 \mu \mathrm{M})$ - and $\mathrm{CaCl}_{2}(2.5 \mathrm{mM})$-induced fluorescence emission were evaluated in $\mathrm{Ca}^{2+}$-free Krebs solution. SNP $(100 \mathrm{nM})$ was used as a positive control group and DMSO $(0.27 \%)$ solution was used as a CON group. Changes in fluorescence were calculated as $F-F^{\prime}$, where $F$ is the maximum fluorescence intensity of the CON group and $F^{\prime}$ is the maximum fluorescence intensity of the drug group.

\subsection{Statistical Analysis}

Results were analyzed with GraphPad Prism 5 version 5.01 for Windows, (GraphPad Software Inc., La Jolla, CA, USA) using two-way ANOVA followed by Bonferroni's post-hoc test. Curve fitting in the figures was generated using the same software using non-linear regression, and $\mathrm{EC}_{50}$ and $\mathrm{E}_{\max }$ were compared using unpaired Student's $t$-test. All the data are expressed as means \pm SEM. Statistical significance was measured as $p<0.05$ compared with the CON group.

\section{Conclusions}

In conclusion, our major novel finding is that IDG, which is one of the main ingredients isolated from OCE, relaxed aortic rings in an endothelium-independent manner, and we provided evidence that the mechanism of its vasorelaxation was via reducing $\left[\mathrm{Ca}^{2+}\right]_{\text {in }}$ in VSMCs. Therefore, IDG shows promise for the development of subsequent $\mathrm{Ca}^{2+}$ channel blockers. However, further studies are needed to investigate the precise mechanisms of IDG action and its pharmacokinetics in vivo.

At the same time, we only studied the vasodilation effect of IDG, and the research on other compounds in O. citriodorum need further development. Previous preliminary experiments have shown that these components also have a certain vasodilation effect, meaning O. citriodorum or other medicinal ingredients have great potential for treating angina pectoris or other cardiovascular diseases, which deserves intensive scientific exploration.

Supplementary Materials: The following are available online: Compound details: Table S1: The information of ethyl acetate extract of O. citriodorum. Figure S1: Key ${ }^{1} \mathrm{H}-{ }^{1} \mathrm{H}$ COSY and HMBC correlations of compound 1, Figure S2: ${ }^{1} \mathrm{H}-\mathrm{NMR}$ spectrum of compound 1, Figure S3: ${ }^{13} \mathrm{C}-\mathrm{NMR}$ spectrum of compound 1, Figure S4: COSY spectrum of compound 1, Figure S5: HSQC spectrum of compound 1, Figure S6: HMBC spectrum of compound 1, Figure S7: ROESY spectrum of compound 1, Figure S8: ${ }^{1} \mathrm{H}-\mathrm{NMR}$ spectrum of compound 2, Figure S9: ${ }^{13} \mathrm{C}-\mathrm{NMR}$ spectrum of compound 2, Figure S10: ${ }^{1} \mathrm{H}-\mathrm{NMR}$ spectrum of compound 3, Figure S11: ${ }^{13} \mathrm{C}-\mathrm{NMR}$ spectrum of compound 
3, Figure S12: ${ }^{1} \mathrm{H}-\mathrm{NMR}$ spectrum of compound 4, Figure S13: ${ }^{13} \mathrm{C}-\mathrm{NMR}$ spectrum of compound 4, Figure S14: ${ }^{1} \mathrm{H}-\mathrm{NMR}$ spectrum of compound 5, Figure S15: ${ }^{13} \mathrm{C}-\mathrm{NMR}$ spectrum of compound 5, Figure S16: ${ }^{1} \mathrm{H}-{ }^{1} \mathrm{H}$ COSY spectrum of compound 5, Figure S17: HSQC spectrum of compound 5, Figure S18: HMBC spectrum of compound 5, Figure S19: ${ }^{1} \mathrm{H}-\mathrm{NMR}$ spectrum of compound 6, Figure S20: ${ }^{13} \mathrm{C}-\mathrm{NMR}$ spectrum of compound 6, Figure S21: ${ }^{1} \mathrm{H}-\mathrm{NMR}$ spectrum of compound 7, Figure S22: ${ }^{13} \mathrm{C}-\mathrm{NMR}$ spectrum of compound 7, Figure S23: Key ${ }^{1} \mathrm{H}-{ }^{1} \mathrm{H}$ COSY and HMBC correlations of compound 8, Figure S24: ${ }^{1} \mathrm{H}-\mathrm{NMR}$ spectrum of compound 8, Figure S25: ${ }^{13} \mathrm{C}-\mathrm{NMR}$ spectrum of compound 8, Figure S26: COSY spectrum of compound 8, Figure S27: HSQC Spectrum of compound 8, Vasodilatory effects of isodillapiolglycol: Figure S28: IDG directly caused relaxation in the vascular smooth muscle cells of aorta rings at different times. Endothelium (A) -intact or (B) -denuded aorta rings pre-contracted with NE (3 mM), endothelium (C) -intact or (D) -denuded aorta rings pre-contracted potassium chloride $(\mathrm{KCl})$ $(60 \mathrm{mM})$. Values are means \pm SEM $(n=6)$. Relaxation for IDG at $10 \mathrm{~min}$ was compared with relaxation after pre-incubation for 20 and 30 min using two-way ANOVA. Note: ${ }^{*} p<0.05$ vs. 20 min group; ${ }^{\#} p<0.05$ vs. 30 min group.

Author Contributions: Conceptualization, J.Z. and Z.Y.; methodology, T.L., Z.C., S.Y., and P.L.; software, Z.C. and F.W.; validation, T.L. and S.Y.; formal analysis, T.L., Z.C., and F.W.; investigation, T.L., Z.C.; resources, S.Y. and P.L.; data curation, T.L., Z.C., and F.W.; writing-original draft preparation, T.L. and Z.C.; writing—review and editing, T.L., Z.C., and J.Z.; visualization, J.Z. and Z.Y.; supervision, J.Z. and Z.Y.; project administration, J.Z. and Z.Y.; funding acquisition, J.Z. All authors have read and agreed to the published version of the manuscript.

Funding: This research was funded by the National Nature Science Foundation of China $(81274191,81973830)$ and the Science and Technology Planning Project of Guangdong Province (2016B020239005).

Conflicts of Interest: The authors declare no conflict of interest.

\section{References}

1. Skalidis, E.I.; Vardas, P.E. Guidelines on the management of stable angina pectoris. Eur. Heart J. 2006, $27,2606$. [CrossRef] [PubMed]

2. Kinlay, S. Coronary artery spasm as a cause of angina. Circulation 2014, 129, 1717-1719. [CrossRef] [PubMed]

3. Furchgott, R.F. Role of endothelium in responses of vascular smooth muscle. Circ. Res. 1983, 53, 557-573. [CrossRef] [PubMed]

4. Mitchell, J.A.; Ali, F.; Bailey, L.; Moreno, L.; Harrington, L.S. Role of nitric oxide and prostacyclin as vasoactive hormones released by the endothelium. Exp. Physiol. 2008, 93, 141-147. [CrossRef]

5. Berridge, M.J.; Bootman, M.D.; Roderick, H.L. Calcium signalling: Dynamics, homeostasis and remodelling. Nat. Rev. Mol. Cell. Bio. 2003, 4, 517-529. [CrossRef]

6. Figtree, G.A.; Griffiths, H.; Liu, Y.Q.; Webb, C.M.; MacLeod, K.; Collins, P. Plant-derived estrogens relax coronary arteries in vitro by a calcium antagonistic mechanism. J. Am. Coll. Cardiol. 2000, 35, 1977-1985. [CrossRef]

7. Chaitman, B.R.; Laddu, A.A. Stable angina pectoris: antianginal therapies and future directions. Nat. Rev. Cardiol. 2011, 9, 40-52. [CrossRef]

8. Divakaran, S.; Loscalzo, J. The Role of Nitroglycerin and Other Nitrogen Oxides in Cardiovascular Therapeutics. J. Am. Coll. Cardiol. 2017, 70, 2393-2410. [CrossRef]

9. Giannopoulos, A.A.; Giannoglou, G.D.; Chatzizisis, Y.S. Pharmacological approaches of refractory angina. Pharmacol. Ther. 2016, 163, 118-131. [CrossRef]

10. Common Herbal Medicine Manual from Guangzhou Troops; Guangzhou Army Logistics Department Health Department: Guangzhou, China, 1969; p. 574.

11. National Compendium of Chinese Herbal Medicine; National Compilation Group of Chinese Herbal Medicine: Guangzhou, China, 1996; pp. 850-851.

12. Chinese Materia Medica Dictionary; Nanjing University of Chinese Medicine: Nanjing, China, 2006; p. 2425.

13. Yin, S.; Zhang, S.; Tong, G.; Deng, L.; Liang, T.; Zhang, J. In vitro vasorelaxation mechanisms of Isoapiole extracted from Lemonfragrant Angelica Root on rat thoracic aorta. J. Ethnopharmacol. 2016, 188, 229-233. [CrossRef]

14. Li, L.; Zhou, X.; Li, N.; Sun, M.; Lv, J.; Xu, Z. Herbal drugs against cardiovascular disease: traditional medicine and modern development. Drug Discov. Today 2015, 20, 1074-1086. [CrossRef] [PubMed]

15. Guoyong, T. Study on the Effect and Mechanism of Isoapiole on Thoracic Aorta in Rats. Master's Thesis, Guangzhou University of Chinese Medicine, Guangzhou, China, 2014. 
16. Shanshan, Y. Chemical Composition Analysis of Angelica citriodora Vasorelaxant Ion Effects on Rat Thoracic Aorta Rings and Its Mechanism. Master's Thesis, Guangzhou University of Chinese Medicine, Guangzhou, China, 2016.

17. Ding, Y.M.; Zhang, H.Q.; Yuan, C.Q.; Dong, Y.F. Study on the chemical constituents of the Ostericum citriodorum . J. Integr. Plant Biol. 1983, 25, 250-253.

18. Moohammadaree, A.; Changtam, C.; Wicha, P.; Suksamrarn, A.; Tocharus, J.; Tocharus, C. Mechanisms of Vasorelaxation Induced by Hexahydrocurcuminin Isolated Rat Thoracic Aorta. Phytother. Res. 2015, 29, 1806-1813. [CrossRef] [PubMed]

19. Hill, M.A.; Zou, H.; Potocnik, S.J.; Meininger, G.A.; Davis, M.J. Invited review: Arteriolar smooth muscle mechanotransduction: $\mathrm{Ca}(2+)$ signaling pathways underlying myogenic reactivity. J. Appl. Physiol. 2001, 91, 973-983. [CrossRef] [PubMed]

20. Chan, S.S.; Choi, A.O.; Jones, R.L.; Lin, G. Mechanisms underlying the vasorelaxing effects of butylidenephthalide, an active constituent of Ligusticum chuanxiong, in rat isolated aorta. Eur. J. Pharmacol. 2006, 537, 111-117. [CrossRef] [PubMed]

21. Brozovich, F.V.; Nicholson, C.J.; Degen, C.V.; Gao, Y.Z.; Aggarwal, M.; Morgan, K.G. Mechanisms of Vascular Smooth Muscle Contraction and the Basis for Pharmacologic Treatment of Smooth Muscle Disorders. Pharmacol. Rev. 2016, 68, 476-532. [CrossRef]

22. Eckert, R.E.; Karsten, A.J.; Utz, J.; Ziegler, M. Regulation of renal artery smooth muscle tone by alpha1-adrenoceptors: role of voltage-gated calcium channels and intracellular calcium stores. Urol. Res. 2000, 28, 122-127. [CrossRef]

23. Noguera, M.A.; Ivorra, M.D.; Chulia, S.; D'Ocon, P. Capacitative Ca2+ entry associated with alpha1-adrenoceptors in rat aorta. Naunyn Schmiedebergs Arch. Pharmacol. 1997, 356, 83-89. [CrossRef] [PubMed]

24. Hill-Eubanks, D.C.; Werner, M.E.; Heppner, T.J.; Nelson, M.T. Calcium signaling in smooth muscle. Cold Spring Harb. Perspect. Biol. 2011, 3, a004549. [CrossRef] [PubMed]

25. Lee, K.; Jung, J.; Yang, G.; Ham, I.; Bu, Y.; Kim, H.; Choi, H.Y. Endothelium-independent vasorelaxation effects of Sigesbeckia glabrescens (Makino) Makino on isolated rat thoracic aorta. Phytother. Res. 2013, 27, 1308-1312. [CrossRef] [PubMed]

26. Nelson, M.T.; Quayle, J.M. Physiological roles and properties of potassium channels in arterial smooth muscle. Am. J. Physiol. 1995, 268, C799-C822. [CrossRef] [PubMed]

27. Jo, C.; Kim, B.; Lee, S.; Ham, I.; Lee, K.; Choi, H.Y. Vasorelaxant Effect of Prunus mume (Siebold) Siebold \& Zucc. Branch through the Endothelium-Dependent Pathway. Molecules 2019, 24, 3340.

28. Wu, S.N. Large-conductance Ca2+- activated $\mathrm{K}+$ channels:physiological role and pharmacology. Curr. Med. Chem. 2003, 10, 649-661. [CrossRef] [PubMed]

29. Kim, B.; Lee, K.; Chinannai, K.S.; Ham, I.; Bu, Y.; Kim, H.; Choi, H.Y. Endothelium-Independent Vasorelaxant Effect of Ligusticum jeholense Root and Rhizoma on Rat Thoracic Aorta. Molecules 2015, 20, 10721-10733. [CrossRef] [PubMed]

30. Romero, F.; Palacios, J.; Jofré, I.; Paz, C.; Nwokocha, C.R.; Paredes, A.; Cifuentes, F. Aristoteline, an Indole-Alkaloid, Induces Relaxation by Activating Potassium Channels and Blocking Calcium Channels in Isolated Rat Aorta. Molecules 2019, 24, 2748. [CrossRef] [PubMed]

31. Rastogi, S.; Pandey, M.M.; Rawat, A.K. Traditional herbs: A remedy for cardiovascular disorders. Phytomedicine 2016, 23, 1082-1089. [CrossRef]

Sample Availability: Samples of the compounds are available from the authors. 